\title{
Enhanced growth of juvenile Tachypleus tridentatus (Chelicerata: Xiphosura) in the laboratory: a step towards population restocking for conservation of the species
}

\author{
Yan Chen ${ }^{1,2}$, C. W. Lau ${ }^{1}$, S. G. Cheung ${ }^{1,3}$, C. H. Ke ${ }^{4}$, Paul K. S. Shin ${ }^{1,3, *}$ \\ ${ }^{1}$ Department of Biology and Chemistry, and ${ }^{3}$ State Key Laboratory in Marine Pollution, City University of Hong Kong, \\ Tat Chee Avenue, Kowloon, Hong Kong SAR \\ ${ }^{2}$ College of Marine Sciences, Shanghai Ocean University, No. 999, Hu Cheng Loop-road, Lingang New City, Shanghai, PR China \\ ${ }^{4}$ State Key Laboratory of Marine Environmental Science, College of Oceanography and Environmental Science, \\ Xiamen University, Xiamen, Fujian, PR China
}

\begin{abstract}
Juveniles of artificially bred Tachypleus tridentatus were reared in the laboratory for 15.5 mo. Fast growth (at least 3 times faster than in previous studies) and low mortality were observed, with juveniles reaching the 9 th instar stage and having a cumulative mortality of $61.3 \%$ at the end of the rearing period. Such enhanced growth can potentially be attributed to high seawater temperature, sufficient living space and constant water flow. Isometric growth of prosomal width and other growth parameters including opisthosoma width, eye distance and prosomal length was found. Two distinct growth phases were detected for the opisthosoma length, with zero growth from the 1st to 2nd instar but isometric growth from the 2nd to 9th instar stage. Growth in telson length was positively allometric from the 1st to 3rd instar and isometric from the 3rd to 9th instar stage. The increase in wet weight and prosomal width was isometric throughout the 9 developmental stages. Based on the allometric growth patterns, the juveniles can reach adult size within 4 yr. The results may serve as a basis for the large-scale culture of this species for the purposes of restocking and restoration of natural populations.
\end{abstract}

KEY WORDS: Horseshoe crab · Tachypleus tridentatus $\cdot$ Juvenile growth $\cdot$ Allometry

\section{INTRODUCTION}

Horseshoe crabs are an archaic group of marine chelicerates, with the oldest fossils dating back to the Upper Ordovician 445 million years ago (Rudkin et al. 2008). There are 4 living horseshoe crab species, including one American species, Limulus polyphemus (Linnaeus, 1758), and 3 Asian species, Carcinoscorpius rotundicauda (Latreille, 1802), Tachypleus tridentatus (Leach, 1819) and T. gigas (Müller, 1785). Horseshoe crab populations are rapidly declining around the world, as has been reported in the USA (Botton \& Haskin 1984, Bell \& Henderson 1993, Shuster et al. 2003, Smith et al. 2009), Japan (Itow 1998), Taiwan
(Chen et al. 2004, Hsieh \& Chen 2009), Singapore (Hong 2004) and the Philippines (Schoppe 2002). Horseshoe crabs were known to occur in great numbers in Hong Kong some 30 yr ago, but now, they can only be found in much lower numbers (Chiu \& Morton 1999, 2003, Li 2008). An updated survey, using both random transect and walk-through search methods at 17 shores in Hong Kong in summer and winter showed that the density of juvenile horseshoe crabs T. tridentatus and C. rotundicauda had declined significantly (by over $90 \%$ ) since 2002 (Shin et al. 2009). The loss of breeding habitats, coupled with the slow growth of these crabs, means that these living fossils may be facing a potential threat of extinction. 
Use of captive breeding for population enhancement in animal conservation has increased markedly in the last decade (Olney et al. 1994). In Taiwan, more than 10000 individuals of second-instar juvenile Tachypleus tridentatus produced artificially in the laboratory were released in the protected area in Kinmen in 2002 (Chen et al. 2004), while about 40000 juveniles were released in the wild in Xiamen, China, in the same year. A successful restocking program relies heavily on an adequate supply of juveniles from artificial breeding, as juveniles released in the wild may suffer high mortality from predation, diseases, food availability, etc. The problems with juvenile horseshoe crabs in culture include low fertilization success, high juvenile mortality and slow growth of the instars (Sekiguchi et al. 1988, Chatterji 1994). The most extensive study of horseshoe crab growth was conducted by Sekiguchi (1988) on the juveniles of Limulus polyphemus and T. tridentatus, which required $9 \mathrm{yr}$ to develop into 14th and 10th instars, respectively. The study itself, however, may not be representative because of both low numbers of specimens and survivors in the study, as an initial number of 44 and 33 ind. were used for L. polyphemus and $T$. tridentatus, respectively, and only one individual of each species survived at the end of the experiment.

The actual life span and exact number of ecdysis events in horseshoe crabs are unknown (Tanacredi 2001, Carmichael et al. 2003, Lee \& Morton 2005), as it is difficult to accurately assess age in horseshoe crabs (Botton \& Ropes 1988). Goto \& Hattori (1929) suggested that Tachypleus tridentatus molts 12 to 13 times before maturity, while Kawahara (1984) proposed that males molt 14 times in $9 \mathrm{yr}$ and females 15 times in 10 yr. Sekiguchi et al. (1988), on the other hand, reported that $T$. tridentatus males molted 15 times within $14 \mathrm{yr}$, based on an allometric growth pattern identified in laboratory culture over a period of $9 \mathrm{yr}$. Asano (1942), however, reported that the species reached maturity in 15 to 16 yr after 17 or 18 ecdyses based on field observations and measurements of exuvial sizes. To follow individuals' growth from hatching to maturity in a natural habitat is challenging because it is impractical to produce a long-lasting external tag for juvenile horseshoe crabs due to their regular ecdyses (Sekiguchi et al. 1988, Lee \& Morton 2005). Therefore, indirect methods including examination of either living individuals (Carmichael et al. 2003) or exuvias (Shuster 1958, 1982) have been used. Another way to obtain growth data is by studying individuals in culture (Sekiguchi 1988). By following the growth and size of individual instar stages and assuming that individual growth between instar stages is the same in culture as in the wild, results may be extrapolated to estimate size and age of individuals in the field.
The main aim of the present study was to investigate growth of the Chinese horseshoe crab Tachypleus tridentatus in culture and assess the possibility of producing culture conditions which will permit successful large-scale production of this species for population enhancement in the wild.

\section{MATERIALS AND METHODS}

Artificial insemination. A mating pair of horseshoe crabs Tachypleus tridentatus was purchased from a fish market, and artificial insemination and breeding was carried out on 23 August 2007. The ventral sides of the prosoma of the mating pairs were cut open. Eggs were collected using a spoon, while sperm was collected using a syringe. Eggs were washed with seawater and in vitro fertilization was carried out by mixing the eggs with diluted sperm (diluted 4 times using filtered natural seawater). The fertilization rate was over $95 \%$, and the fertilized eggs were then incubated in the laboratory.

Crab maintenance. A fiber glass tank $(200 \times 100 \times$ $25 \mathrm{~cm}$ ) equipped with a water re-circulating system was used for the culturing of fertilized eggs and subsequent juveniles. The re-circulating system consisted of a protein skimmer, ceramic rings, UV light and filter cottons. Natural seawater (30\%) collected from a clean site along the east coast of Hong Kong was used in the culture process and maintained at 28 to $30^{\circ} \mathrm{C}$ by electric heaters. The water flow was maintained at $12 \mathrm{l}$ $\mathrm{min}^{-1}$. Half of the water in the tank was renewed every week, and air stones were put inside the tank to provide aeration. The dark:light cycle was set at $12 \mathrm{~h}$ dark:12 h light.

Prior to hatching, the fertilized eggs were suspended in running water inside the tank using small baskets to maintain a high level of oxygen around the eggs, whereas after hatching, the juveniles were cultured directly in the tank with running water and coral sand ( 0.5 to $2.0 \mathrm{~mm}$ in particle size, $5 \mathrm{~cm}$ in depth), as juvenile horseshoe crabs prefer burrowing into the substrate.

No food was provided to the trilobite larvae as they do not feed (Carmichael et al. 2009). Starting from the 2nd instar stage, juveniles were fed daily at night. The 2nd and 3rd instars were fed with newly hatched larval brine shrimp Artemia salina which was left in the tank overnight, and unconsumed shrimp were removed the following morning. During feeding, water circulation was stopped but was resumed the next morning. The 4 th and 5th instars were fed with defrosted adult brine shrimps A. salina, whereas the 6 th instars and beyond were fed with the meat of clam Ruditapes philippinarum and shrimp Metapenaeus ensis, which were chopped into small pieces. The food was left in the 
tank overnight, and unconsumed food was removed the following morning. Water circulation was maintained when the juveniles were fed.

Growth measurements and data analysis. The morphometric parameters measured are shown in Fig. 1. Parameters were measured weekly at earlier stages and monthly at later stages. The condition of the horseshoe crabs was checked daily. Deceased individuals as well as exuvias were collected and the number recorded every day. To avoid handling stress, especially for small-sized individuals, exuvias collected during the rearing period were used for the detailed size measurements of various body parts in order to construct growth models. Fifty specimens were measured from the 1 st to the 7 th instar, whilst 28 specimens were used for the 8th and 9th instars. Measurements of small-sized individuals, i.e. the 1st, 2nd and 3rd instars, were conducted under a stereomicroscope.

The allometric growth of each parameter $(y)$ was expressed as a power function of prosomal width $(x)$ (Fuiman 1983) in the form of an equation $y=a x^{b}$. A $b$ coefficient was estimated from the linear regression of an allometric growth curve, where $\log y=\log a$ $+b \log x$. This coefficient identifies the allometric growth pattern of Tachypleus tridentatus such that values of $b=1$ for length and $b=3$ for weight indicate isometric allometry; values of $b>1$ for length and $b>3$ for weight indicate positive allometry, and values of $b<1$ for length and $b<3$ for weight indicate negative allometry (Sekiguchi et al. 1988, Osse \& van den Boogart 2004, Lee \& Morton 2005). Inflexion points of the growth curves were determined using the iteration procedure according to van Snik et al. (1997).

\section{RESULTS}

\section{Mortality}

A low hatching rate $(0.79 \%$, or 155 ind. from some 20000 eggs) was recorded. However, survival rates were high at subsequent instar stages. The highest mortality $(32.7 \%)$ was observed for the 1 st instar, whereas mortality decreased to $<20 \%$ for both the 2 nd and 3rd instars, $<5 \%$ for the 4 th to 9 th instars and $0 \%$ for the 6th, 8th and 9th instars (Table 1). The cumulative mortality from the 1 st to 9 th instar was $61.3 \%$.

\section{Developmental stages}

In total, 155 trilobite larvae were hatched from 2 October to 5 November 2007, and the hatching time varied between 39 and $74 \mathrm{~d}$ after fertilization, or $55.2 \mathrm{~d}$ on average. The average age recorded for each developmental stage is presented in Table 1. The lowest growth was recorded for a single individual which remained as a 1st instar for almost 11 mo before developing into a 2nd instar, when most of the individuals had already reached the 7 th instar stage. This individual developed into a 3rd instar at the age of $13.5 \mathrm{mo}$, and a 4th instar at the age of $16 \mathrm{mo}$, when most of the individuals were already 9 th instars.

\section{Growth}

Allometric growth of size and weight

Mean values $( \pm \mathrm{SD})$ of each morphometric parameter for each instar stage are summarized in Table 1, and the allometric relationships are shown in Fig. 2. The growth of the eye distance $(a=0.6201, b=0.9591$,

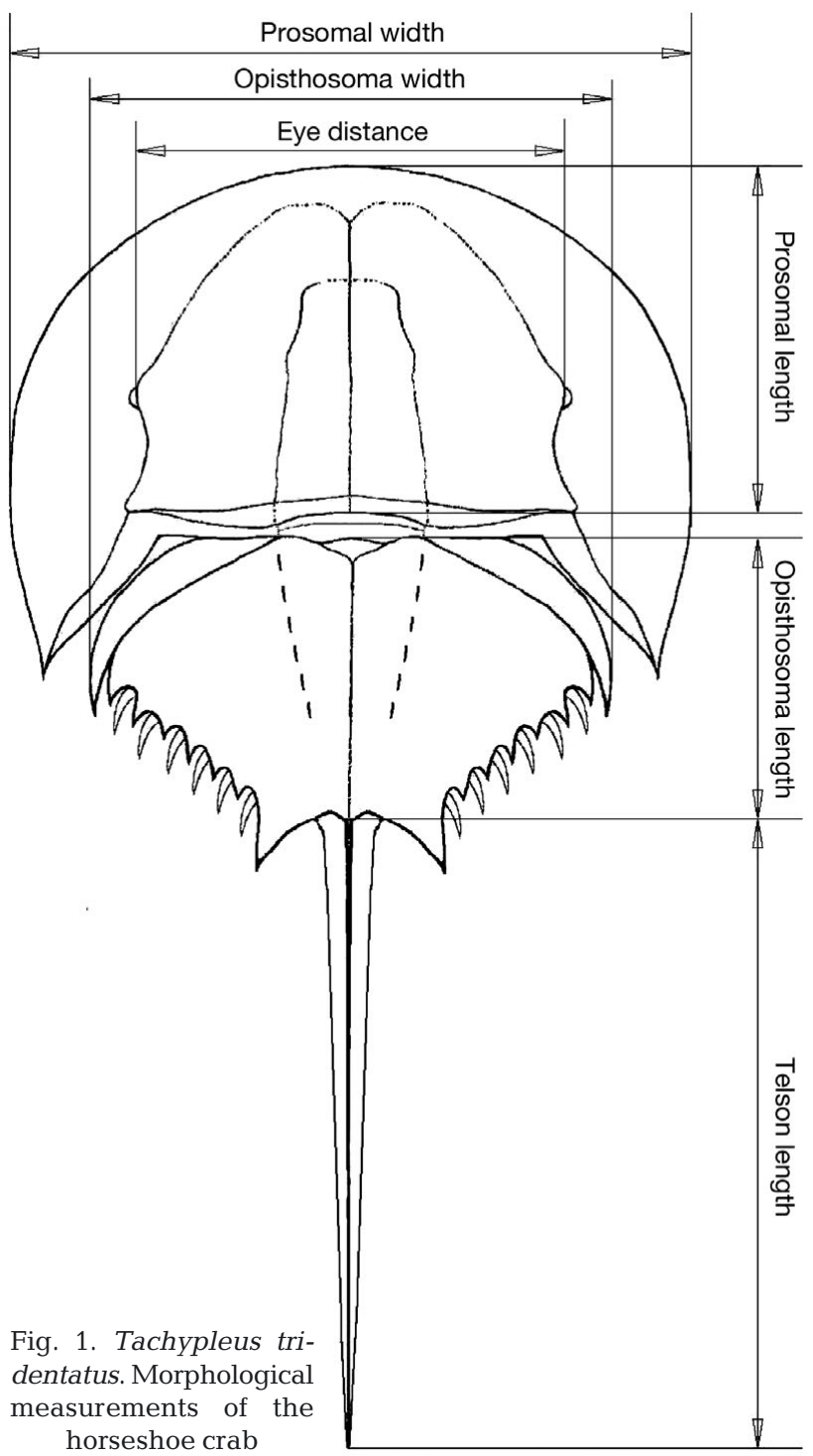


Table 1. Tachypleus tridentatus. Growth (mean \pm SD) of juvenile horseshoe crabs from the 1st to 9 th instar stage. $\mathrm{n}=50 \mathrm{for}$ each of the size/ weight measurement of individuals from the 1st to 7 th instar stage; $n=28$ for the measurements of individuals from the 8th and 9th instar stage

\begin{tabular}{|c|c|c|c|c|c|c|c|c|c|}
\hline \multirow{2}{*}{$\begin{array}{l}\text { Instar } \\
\text { stage }\end{array}$} & \multirow{2}{*}{ Age (d) } & \multirow{2}{*}{$\begin{array}{c}\text { Mortality } \\
(\%)\end{array}$} & \multirow[b]{2}{*}{$\begin{array}{l}\text { Prosomal } \\
\text { width }\end{array}$} & \multirow[b]{2}{*}{$\begin{array}{l}\text { Eye dis- } \\
\text { tance }\end{array}$} & \multirow{2}{*}{$\begin{array}{c}\text { Opisthosoma } \\
\text { width }\end{array}$} & \multirow[b]{2}{*}{$\begin{array}{l}\text { Prosomal } \\
\text { length }\end{array}$} & \multirow[b]{2}{*}{$\begin{array}{l}\text { Opisthosoma } \\
\text { length }\end{array}$} & \multirow[b]{2}{*}{$\begin{array}{l}\text { Telson } \\
\text { length }\end{array}$} & \multirow{2}{*}{$\begin{array}{l}\text { Wet weight } \\
(\mathrm{g})\end{array}$} \\
\hline & & & & & & & & & \\
\hline I & $53.2 \pm 4.3$ & 32.7 & $6.26 \pm 0.16$ & $3.82 \pm 0.12$ & $4.79 \pm 0.09$ & $3.78 \pm 0.16$ & $2.88 \pm 0.13$ & 0 & $0.02 \pm 0.002$ \\
\hline II & $133.9 \pm 7.7$ & 18.4 & $8.86 \pm 0.32$ & $4.89 \pm 0.18$ & $6.39 \pm 0.21$ & $5.30 \pm 0.18$ & $2.88 \pm 0.16$ & $3.55 \pm 0.32$ & $0.06 \pm 0.01$ \\
\hline III & $154.6 \pm 8.6$ & 15.6 & $12.3 \pm 0.53$ & $6.64 \pm 0.19$ & $8.87 \pm 0.33$ & $7.41 \pm 0.25$ & $4.02 \pm 0.13$ & $8.05 \pm 0.45$ & $0.14 \pm 0.02$ \\
\hline IV & $198.7 \pm 13.1$ & 3.3 & $16.4 \pm 0.69$ & $8.83 \pm 0.29$ & $11.7 \pm 0.44$ & $9.90 \pm 0.39$ & $5.41 \pm 0.20$ & $13.0 \pm 0.82$ & $0.32 \pm 0.03$ \\
\hline V & $233.3 \pm 8.2$ & 1.7 & $22.0 \pm 1.25$ & $12.0 \pm 0.66$ & $16.0 \pm 0.98$ & $13.5 \pm 0.80$ & $7.32 \pm 0.45$ & $18.8 \pm 2.01$ & $0.72 \pm 0.06$ \\
\hline VI & $288.8 \pm 9.9$ & 0 & $28.9 \pm 1.52$ & $15.6 \pm 0.72$ & $21.1 \pm 1.24$ & $17.9 \pm 0.89$ & $9.84 \pm 0.46$ & $25.2 \pm 3.15$ & $1.71 \pm 0.17$ \\
\hline VII & $335.1 \pm 9.2$ & 1.9 & $38.3 \pm 2.49$ & $20.7 \pm 1.14$ & $28.0 \pm 1.75$ & $24.0 \pm 1.35$ & $13.3 \pm 0.73$ & $32.0 \pm 3.53$ & $4.43 \pm 0.73$ \\
\hline VIII & $385.4 \pm 12.6$ & 0 & $49.8 \pm 3.35$ & $26.7 \pm 1.60$ & $35.9 \pm 2.52$ & $31.4 \pm 2.22$ & $17.6 \pm 1.04$ & $44.5 \pm 4.67$ & $9.33 \pm 1.56$ \\
\hline IX & $463.5 \pm 7.5$ & 0 & $65.7 \pm 5.64$ & $35.2 \pm 2.77$ & $47.0 \pm 4.03$ & $41.6 \pm 3.71$ & $23.3 \pm 1.92$ & $61.4 \pm 6.09$ & $20.8 \pm 4.17$ \\
\hline
\end{tabular}

$\left.\mathrm{r}^{2}=0.9962\right)$, opisthosoma width $(a=0.7601, b=0.9855$, $\left.\mathrm{r}^{2}=0.9978\right)$ and prosomal length $(a=0.5701, b=$ 1.0237, $\mathrm{r}^{2}=0.998$ ) throughout the 9 instar stages (Fig. $2 \mathrm{a}-\mathrm{c})$ was isometric with prosomal width. Two distinct growth phases were detected for the opisthosoma length: zero growth was obtained from the 1st to 2nd instar $\left(a=2.7847, b=0.0165, r^{2}=0.0035\right.$; horizontal line), but growth became isometric with the prosomal width from the 2nd to 9th instar $(a=0.2879, b=1.0501$, $\mathrm{r}^{2}=0.9952$ ) (Fig. 2d). Growth in telson length was positively allometric with the prosomal width from 1st to 3rd instar stages $\left(a=0.0169, b=2.4555, \mathrm{r}^{2}=0.9641\right)$, and isometric from the 3rd to 9th instar $(a=0.6109, b=$ 1.0969, $\mathrm{r}^{2}=0.9676$ ) (Fig. 2e). In addition, the growth in wet weight was isometric with the prosomal width throughout the 9 instar stages $(a=0.0995, b=2.8986$, $r^{2}=0.9969$ ) (Fig. 2f).

\section{Growth estimations}

Horseshoe crabs show stepwise growth (Shuster 1954, Shuster \& Sekiguchi 2003); therefore, the size increment during their intermolt periods is barely discernible, and the prosomal width is always correlated with the development stage as well as with age (Lee \& Morton 2005). Regressions relating prosomal width and body wet weight and instar stage are shown in Fig. 3a and that relating age and instar stage is shown in Fig. 3b. The corresponding equations are:

$$
\begin{aligned}
& L=0.4982 \mathrm{e}^{0.2905 i}\left(\mathrm{r}^{2}=0.9986\right) \\
& W t=0.0106 \mathrm{e}^{0.8429 i}\left(\mathrm{r}^{2}=0.9986\right) \\
& T=3.145 \mathrm{e}^{0.1791 i}\left(\mathrm{r}^{2}=0.9955\right)
\end{aligned}
$$

where $L$ represents prosomal width in $\mathrm{cm}$, $W t$ represents wet weight in $g, T$ represents age in month, and $i$ represents the instar stage.

Growth data collected from the 1st to 9th instars were used to estimate the stepwise growth of horseshoe crabs beyond the 9th instar stage (Fig. 3a). The estimated ages of instars beyond Stage 9, however, were based on the results obtained from the 2nd to 9th instars, as the age-instar stage relationship for the 1st instar was different from other stages (Fig. 3b). Growth increased about one-third with each molt. According to the extrapolated data, these horseshoe crabs could develop into 11th instars in $2 \mathrm{yr}$, with a prosomal width of $12.2 \mathrm{~cm}$ and wet weight of $113 \mathrm{~g}$. Two more ecdyses would occur in both the third and fourth year, with a prosomal width of $38.9 \mathrm{~cm}$ and wet weight of $3.3 \mathrm{~kg}$ for a 15 th instar.

\section{Developmental deformities}

All individuals from the 1st to 4 th instar stage possessed perfectly symmetrical prosoma. Three individuals at the 5 th instar stage $(4.3 \%)$ were found to have either a spiral or shorter telson. The number of individuals with such deformities increased to $11(16 \%)$ at the 6 th instar stage. A partial concave margin of the prosoma was recorded in 5 ind. after the 6 th instar stage. Degradation of a single eye was observed in 3 ind. ( 2 on the right eye) after the 7 th instar stage (4.3\%). All these individuals behaved normally, but these deformities remained during the study period.

\section{DISCUSSION}

\section{Mortality}

In the present study, a very low hatching success was recorded. This could possibly be due to fungal infection at the incubation stage of the fertilized eggs in the holding baskets within the re-circulating water tank (Schreibman \& Zarnoch 2009). However, more than one-third of the 1st instar horseshoe crabs survived to 9th instar stage (cumulative mortality $61.3 \%$ ). The survival rate was higher than that of a wild population of the American species Limulus polyphemus in Pleasant 

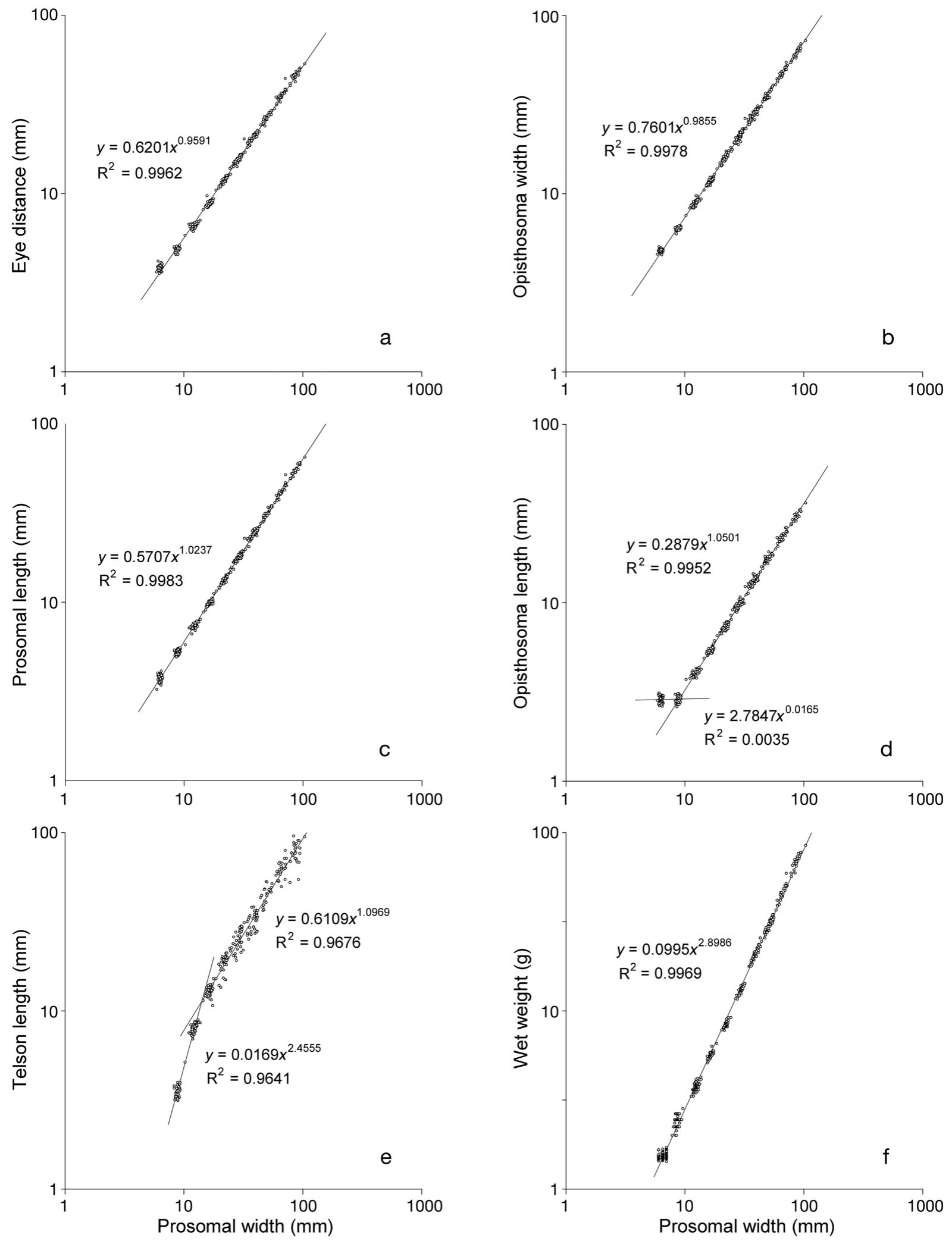

Fig. 2. Tachypleus tridentatus. Allometric growth equations and relationship between the prosomal width with different body part sizes, and with wet weight of horseshoe crab juveniles from the 1st to 9th instar stage. (a) Eye distance; (b) opisthosoma width; (c) prosomal length; (d) opisthosoma length; (e) telson length (no telson at the 1st instar stage); (f) wet weight. $(\mathrm{n}=50$ for each measurement of individuals from the 1 st to 7 th instar stage; $n=28$ for individuals from the 8th and 9th instar stage) 

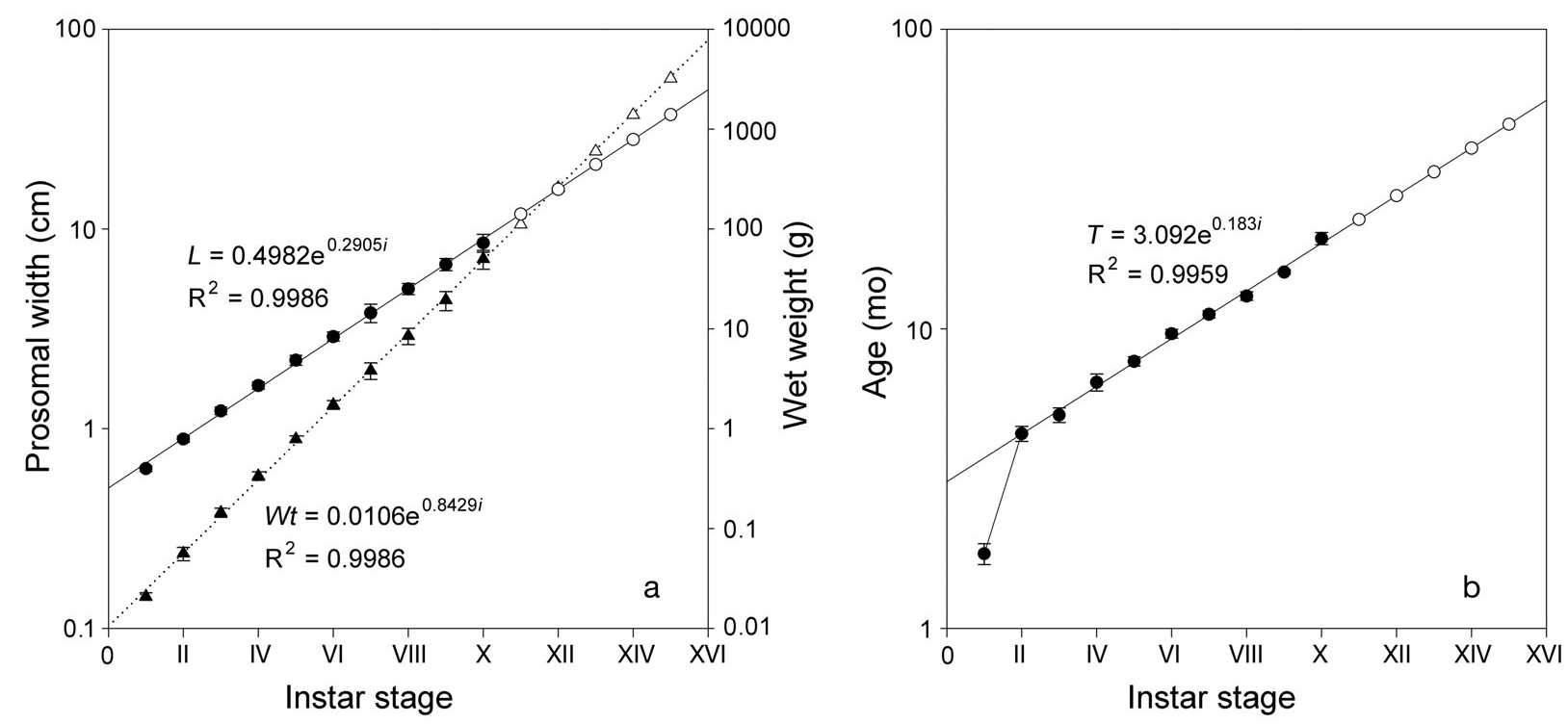

Fig. 3. Tachypleus tridentatus. Estimations of the stepwise growth of horseshoe crabs in (a) prosomal width (circles) and wet weight (triangles), and (b) age. $\bullet, \mathbf{\Lambda}$ : data recorded from the present study; $\mathrm{O}, \Delta$ : data from estimations (see section 'Growth estimations' for definitions of variables)

Bay, USA, where the cumulative mortality was $99.6 \%$ from the 1 st to the 7 th instar stage (which lasted $1 \mathrm{yr}$ ) (Carmichael et al. 2003). The mortality at each stage in the Carmichael et al. study was also higher in L. polyphemus $(58,80,27,63,67$, and $36 \%$ at the 1 st, 2nd, 3rd, 4th, 5th and 7th instar stage, respectively) than in the Tachypleus tridentatus examined in our study. A lower mortality was also obtained for laboratoryhatched and -cultured Carcinoscorpius rotundicauda and T. gigas for which the mortality after 1 yr was 39.9 and $34.5 \%$, respectively, with the abundant instar stages being the 6th instar and 5th instar, respectively (Zadeh et al. 2009). According to Carmichael et al. (2003), mortality beyond the 8th instar stage was rare, which is consistent with our study in which zero mortality was obtained for both the 8th and 9th instars. The elevated survival rate under laboratory conditions at the early developmental stages observed in the present study can be significant for the conservation of this species, as a large number of juveniles can be obtained from a small number of adult horseshoe crabs for a restocking program, especially important in areas where adult horseshoe crabs are endangered.

\section{Developmental stages}

In the present study, large variations in hatching times were noted. Similar observations were reported by Zadeh et al. (2009), in which some laboratorycultured Tachypleus gigas and Carcinoscorpius rotundicauda larvae survived the 1st instar stage but did not molt for $170 \mathrm{~d}$. Such delayed molting is also evident in wild Limulus polyphemus populations where larvae emerged from the sandy nests without having molted during winter (Botton et al. 1992). In the present breeding experiment all full siblings were cultured together. Our results were obtained from only one pair of adult T. tridentatus, and presumably there was little generic variation among them. Mishra (2009) postulated that the variability in hatching time might be associated with a molting protein in horseshoe crabs. A lower protein level would delay subsequent molting events, leading to slow-developing outliers. It is likely that the molting protein in question is the molting hormone 20-hydroxecdysone (Shuster \& Sekiguchi 2003). However, further studies are required to elucidate the involvement of such a protein and other physiological events related to molting changes in horseshoe crab development.

\section{Growth}

There are very few records of consecutive data on the stepwise growth of horseshoe crabs, due to the difficulties in raising them from eggs to adults in the laboratory (Sekiguchi et al. 1988, Chatterji 1994, Shuster \& Sekiguchi 2003). A comparison of the prosomal width of different instars is shown in Table 2. Sizes of instars obtained from field and laboratory studies by Chen et al. (2004) were similar to ours, but those obtained in a laboratory study by Sekiguchi (1988) were smaller.

Unusually fast growth was recorded in the present study. In contrast to general growth events with 6 ecdyses in the first 3 yr after hatching (Rudloe 1981, 
Table 2. Tachypleus tridentatus. Estimation of the stepwise growth of the horseshoe crabs

\begin{tabular}{|c|c|c|c|c|}
\hline Year & $\begin{array}{l}\text { Instar } \\
\text { stage }\end{array}$ & $\begin{array}{l}\text { Age } \\
\text { (mo) }\end{array}$ & $\begin{array}{c}\text { Prosoma } \\
\text { width }(\mathrm{cm})\end{array}$ & $\begin{array}{c}\text { Wet weight } \\
(\mathrm{g})\end{array}$ \\
\hline 1 & $\mathrm{I}^{-V I I}{ }^{\mathrm{a}}$ & 11.2 & 3.8 & 3.8 \\
\hline \multirow[t]{3}{*}{2} & VIII-IX a & 15.5 & 6.6 & 19.3 \\
\hline & $\mathrm{X}^{\mathrm{b}}$ & 18.9 & 9.1 & 48.5 \\
\hline & $\mathrm{XI}^{\mathrm{b}}$ & 22.6 & 12.2 & 113 \\
\hline \multirow[t]{2}{*}{3} & XII ${ }^{b}$ & 27.0 & 16.3 & 262 \\
\hline & $\mathrm{XIII}^{\mathrm{b}}$ & 32.3 & 21.8 & 608 \\
\hline \multirow[t]{2}{*}{4} & $\mathrm{XIV}^{\mathrm{b}}$ & 38.6 & 29.1 & 1413 \\
\hline & $\mathrm{XV}^{\mathrm{b}}$ & 46.2 & 38.9 & 3283 \\
\hline
\end{tabular}

Shuster 1982, Mikkelsen 1988, Sekiguchi et al. 1988, Carmichael et al. 2003) and 1 ecdysis once a year thereafter until maturation (Shuster 1954, 1958, 1982, Mikkelsen 1988, Sekiguchi 1988, Chatterji 1994), juvenile Tachypleus tridentatus in our study experienced 6 ecdyses within a year (including approximately 2 mo before hatching), and 2 more ecdyses in the following $4 \mathrm{mo}$. Such fast growth can be attributed to laboratory rearing with high water temperatures and an adequate food supply.

Chiu \& Morton (2004) reported the seasonal pattern of feeding behaviour of juvenile horseshoe crabs at an intertidal zone in Hong Kong. The highest number of feeding trails was recorded in summer, while only a few juveniles were seen in winter, when the temperature can be $<10^{\circ} \mathrm{C}$, implying that horseshoe crabs barely eat at low temperatures in the field. In contrast, laboratory-cultured juveniles in our study were maintained at 28 to $30^{\circ} \mathrm{C}$ and fed every day. A slower growth in horseshoe crab juveniles at lower temperatures has also been reported in previous studies (Shuster 1982, Yeh 1999), which showed that ecdysis continued when the temperature remained at $>28^{\circ} \mathrm{C}$ but halted at $<22^{\circ} \mathrm{C}$. Low temperatures reduce molting hormone levels to a critical level in Limulus polyphemus and hence suspend the ecdysis at temperatures $<20^{\circ} \mathrm{C}$ (Jegla \& Costlow 1982).

Chen et al. (2004) suggested that 28 to $31^{\circ} \mathrm{C}$ is the most suitable temperature for incubating eggs and rearing juveniles. The present study showed that the growth of Tachypleus tridentatus could proceed throughout the year, provided that the seawater temperature was optimal $\left(28\right.$ to $\left.30^{\circ} \mathrm{C}\right)$. A much slower growth for $T$. tridentatus, however, was obtained by Sekiguchi et al. (1988). In the first year of rearing, the juvenile $T$. tridentatus remained as 1 st instars when reared at room temperature but developed into 2nd instars when reared at $30^{\circ} \mathrm{C}$. Altogether 5 ecdyses (i.e. the 6th instar stage) were obtained in the first $3 \mathrm{yr}$; thereafter, there was 1 ecdysis once a year until the crabs reached the 10th instar stage in the seventh year. Such differences might be attributed to differences in rearing conditions, such as living space and water quality. Juveniles in the present study were maintained in a container $(200 \times 100 \times 25 \mathrm{~cm})$ much greater in size than those used in the study of Sekiguchi et al. (1988), in which the size of containers varied from $3.4 \times 3.4 \times 3 \mathrm{~cm}$ to $36 \times 25.5 \times 10 \mathrm{~cm}$, depending on the size of the juveniles. In addition, aerated seawater was used in the present study and the water was re-circulated. In contrast, no circulation or aeration was provided in Sekiguchi at al.'s (1988) study and seawater was changed daily. Nevertheless, under the same rearing conditions as were used for $T$. tridentatus, a much faster growth was recorded for juvenile Limulus polyphemus (Sekiguchi et al. 1988) with 5, 3, 2 and 1 ecdyses in the first, second, third and fourth year, respectively.

Based on the data collected on the stepwise growth of the first 9 instar stages of Tachypleus tridentatus, the present study revealed isometrical growth $(b \approx 1)$ between prosomal width and other growth parameters including eye distance, opisthosoma width, prosomal length and opisthosoma length (except for the zero growth of opisthosoma length between the 1st and 2nd instar). Rapid elongation of the telson was observed at the initial growth phase $(b>1$ before the 4 th instar stage) but became isometric at later growth phases $(b \approx$ 1 after the 4 th instar stage). Therefore, with the exception of the telson, the shape of horseshoe crab at different developmental stages is similar. This is consistent with the results obtained by Sekiguchi et al. (1988) on T. tridentatus and Limulus polyphemus. An increase in the wet weight with the prosomal width was isometric $(b \approx 3)$ in the present study. A similar growth pattern of wet weight $(b=2.9682)$ was obtained by Lee \& Morton (2005) based on 6 consecutive instars of juvenile T. tridentatus which varied between 20 and $100 \mathrm{~mm}$ in prosomal width.

Based on the allometric growth patterns identified in the present study, Tachypleus tridentatus could develop into the 14th and 15th instar in $4 \mathrm{yr}$, with a corresponding prosomal width of 29.1 and $38.9 \mathrm{~cm}$ and a wet weight of 1.4 and $3.3 \mathrm{~kg}$, respectively. Such predicted growth information is consistent with data obtained by Chiu \& Morton (2003) from a wild T. tridentatus population in Hong Kong.

\section{Developmental deformities}

Deformities observed in juvenile horseshoe crabs in the present study may not be attributed to any genetic mutation or genetic diseases, since all the symptoms 
were observed only in elder juveniles beyond the 5 th instar stage. Suboptimal rearing conditions including a very restricted diet and small rearing space may be possible contributing factors. Juvenile horseshoe crabs in the wild are benthic feeders and subsist mainly on polychaetes, oligochaetes, crustaceans, bivalves and gastropods (Carmichael et al. 2004, Zhou \& Morton 2004). The restricted diet provided for the laboratorycultured juveniles included only shrimp and clam meat, which might not provide a balanced diet for the rapid growth of the juveniles. Using carbon and nitrogen stable isotopes as tracers, juveniles were found to use a diet of mixed composition, which changed with horseshoe crab size, and contained potentially high concentrations of particulate organic matter (Carmichael et al. 2009). In some cases, a spiral or shorter telson was found and possibly attributed to the rectangular shape of the culturing tank. Some individuals stayed in the corner of the tank when they tried to shed their exuvias during ecdysis. Their telsons, therefore, could not be straightened but became spiral or even broken. It has been suggested that limited space, handling practices or insufficient water flow can encumber molting or increase exposure to and infection by bacteria or other parasites (Smith \& Berkson 2005). Further investigations are needed to determine the optimal diet and space requirements for growth.

\section{Culture for captive release}

Horseshoe crabs are valued for ecological, economic and educational purposes. The rapid decline in horseshoe crab populations around the world and especially in Asia, however, is evident and becoming a growing concern. A successful restocking program to enhance natural populations relies heavily on an adequate supply of juveniles for release. Several captive release or induced spawning programs have been reported in China (Hong et al. 2009), Japan (see overview by Tsuchiya 2009) and Taiwan (Chen et al. 2009) for Tachypleus tridentatus and in the USA for Limulus polyphemus (e.g. Cuomo 2009, Schreibman \& Zarnoch 2009, Tzafrir-Prag et al. 2009). Of these programs, the captive release effort at the Kasaoka Municipal Horseshoe Crab Museum, Japan, has a long history (Tsuchiya 2009). Juveniles T. tridentatus were reared in tanks with mud and water, and the water was exchanged either once every $20 \mathrm{~d}$ or once a month. The crabs were fed brine shrimp, TetraMin, chopped clams and worms over their growth period. It was reported that a hatched juvenile developed into an adult in its 11th year (Tsuchiya 2009). Hong et al. (2009) also showed that juveniles grow and survive better in the presence of sand as compared to mud in the seawater tanks, and
Cuomo (2009) and Tzafrir-Prag et al. (2009) demonstrated that food quality, type and digestibility have a strong effect on post-hatch molts in laboratory culture. The present study has demonstrated a much enhanced growth of $T$. tridentatus in laboratory culture, possibly due to high seawater temperatures, a large culture space and constant water flow. The results may serve as a basis for the large-scale culture of the species for restocking and restoration of natural populations.

Acknowledgements. This study was funded by the Ocean Park Conservation Foundation of Hong Kong.

\section{LITERATURE CITED}

Asano U (1942) On the life history of Tachypleus tridentatus. Bot Zool 10:120-124 (in Japanese)

Bell WH, Henderson AM (1993) Focus on the Chesapeake Bay, 1991-1992. Annual report. Center for Environmental and Estuarine Studies, University of Maryland, College Park, MD

Botton ML, Haskin HH (1984) Distribution and feeding of the horseshoe crab, Limulus polyphemus on the continental shelf, New Jersey. Fish Bull 82:383-389

Botton ML, Ropes JW (1988) An indirect method for estimating longevity of the horseshoe crab (Limulus polyphemus) based on epifauna slipper shells (Crepidula fornicate). J Shellfish Res 7:407-412

Botton ML, Loveland RE, Jackobson TR (1992) Overwintering by trilobite larvae of horseshoe crab Limulus polyphemus on sandy beach of Delaware Bay (New Jersey, USA). Mar Ecol Prog Ser 88:289-292

Carmichael RH, Rutecki D, Valiela I (2003) Abundance and population structure of the Atlantic horseshoe crab Limulus polyphemus in Pleasant Bay, Cape Cod. Mar Ecol Prog Ser 246:225-239

Carmichael RH, Rutecki D, Annett B, Gaines E, Valiela I (2004) Position of horseshoe crabs in estuarine food webs: $\mathrm{N}$ and $\mathrm{C}$ stable isotopic study of foraging ranges and diet composition. J Exp Mar Biol Ecol 299:231-253

Carmichael RH, Gaines E, Sheller Z, Tong A, Clapp A, Valiela I (2009) Diet composition of juvenile horseshoe crabs: implications for growth and survival of natural and cultured stocks. In: Tanacredi JT, Botton ML, Smith DR (eds) Biology and conservation of horseshoe crabs. Springer, New York, NY, p 267-273

Chatterji A (1994) The horseshoe crab-a living fossil. A Project Swarajya Publication, Orissa

Chen CP, Yeh HY, Lin PF (2004) Conservation of the horseshoe crab at Kinmen, Taiwan: strategies and practices. Biodivers Conserv 13:1889-1904

Chen CP, Hsieh HL, Chen A, Yeh HY, Lin PF, Wang W (2009) The conservation network of horseshoe crab Tachypleus tridentatus in Taiwan. In: Tanacredi JT, Botton ML, Smith DR (eds) Biology and conservation of horseshoe crabs. Springer, New York, NY, p 543-557

Chiu HMC, Morton B (1999) The biology, distribution, and status of horseshoe crabs, Tachypleus tridentatus and Carcinoscorpius rotundicauda (Arthropoda: Chelicerata) in Hong Kong: recommendations for conservation and management. Final Report to China Light and Power. The Swire Institute of Marine Science, University of Hong Kong, Hong Kong 
Chiu HMC, Morton B (2003) The morphological differentiation of two horseshoe crab species, Tachypleus tridentatus and Carcinoscorpius rotundicauda (Xiphosura), in Hong Kong with a regional Asian comparison. J Nat Hist 37: 2369-2382

Chiu HMC, Morton B (2004) The behaviour of juvenile horseshoe crabs: Tachypleus tridentatus (Xiphosura), on a nursery beach at Shui Hau Wan, Hong Kong. Hydrobiologia 523:29-35

Cuomo C (2009) Captive spawning and juvenile culture of Limulus polyphemus. In: Tanacredi JT, Botton ML, Smith DR (eds) Biology and conservation of horseshoe crabs. Springer, New York, NY, p 616-617

Fuiman LA (1983) Growth gradients in fish larvae. J Fish Biol 23:117-123

Goto S, Hattori O (1929) Notes on the spawning habits and growth stages of the Japanese king crab. Congr Int Zool 2:1147-1155

Hong RF (2004) Population and distribution of horseshoe crab Carcinoscorpius rotundicauda at the Kranji Nature rail estuaries, Western Johor Straits. Project Report 49. The National University of Singapore, Department of Biological Sciences, Singapore

Hong S, Zhang X, Zhao Y, Xie Y, Zhang Y, Xu H (2009) Effect of sediment type on growth and survival of juvenile horseshoe crabs (Tachypleus tridentatus). In: Tanacredi JT, Botton ML, Smith DR (eds) Biology and conservation of horseshoe crabs. Springer, New York, NY, p 535-540

Hsieh HL, Chen CP (2009) Conservation program for the Asian horseshoe crab Tachypleus tridentatus in Taiwan: characterizing the microhabitat of nursery grounds and restoring spawning grounds. In: Tanacredi JT, Botton ML, Smith DR (eds) Biology and conservation of horseshoe crabs. Springer, New York, NY, p 417-438

Itow $\mathrm{T}$ (1998) The pollution of coastal water and malformation of horseshoe crab embryos. Bull Fac Edu Shiguoka Univ Nat Sci Ser 48:15-33

Jegla TC, Costlow JD (1982) Temperature and salinity effects on developmental and early posthatch stages of Limulus. In: Bonaventura J, Bonaventura C, Tesh S (eds) Physiology and biology of horseshoe crabs: studies on normal and environmentally stressed animals. Alan R Liss, New York, NY, p 103-113

Kawahara H (1984) Growth and diurnal rhythm of the horseshoe crab. Nat Anim 14:22-26 (in Japanese)

Lee CN, Morton B (2005) Experimentally derived estimates of growth by juvenile Tachypleus tridentatus and Carcinoscorpius rotundicauda (Xiphosura) from nursery beaches in Hong Kong. J Exp Mar Biol Ecol 318:39-49

Li HY (2008) The conservation of horseshoe crabs in Hong Kong. MPhil thesis, City University of Hong Kong, Hong Kong

Mikkelsen T (1988) The secret in the blue blood. Science Press, Beijing

Mishra JK (2009) Larval culture of Tachypleus gigas and its molting behavior under laboratory conditions. In: Tanacredi JT, Botton ML, Smith DR (eds) Biology and conservation of horseshoe crabs. Springer, New York, NY, p 513-519

Olney PJ, Mace G, Feistner A (1994) Creative conservation: interactive management of wild and captive animals. Chapman \& Hall, London

Osse JWM, van den Boogart JGM (2004) Allometric growth in fish larvae: timing and function. Am Fish Soc Symp 40: 167-194

Rudkin D, Young G, Nowlan G (2008) The oldest horseshoe crab: a new xiphosurid from Late Ordovician Konservat-
Lagerstätten deposits, Manitoba, Canada. Palaeontology $51: 1-9$

Rudloe A (1981) Aspects of the biology of juvenile horseshoe crabs, Limulus polyphemus. Bull Mar Sci 31:125-133

Schoppe S (2002) First data on the distribution of horseshoe crabs (Chelicerata: Merostomata) in Palawan, with notes on their status in the Philippines. UPV J Nat Sci 7: 198-206

Schreibman MP, Zarnoch CB (2009) Aquaculture methods and early growth of juvenile horseshoe crabs (Limulus polyphemus). In: Tanacredi JT, Botton ML, Smith DR (eds) Biology and conservation of horseshoe crabs. Springer, New York, NY, p 501-511

Sekiguchi K (1988) Biology of horseshoe crabs. Science House, Tokyo

Sekiguchi K, Seshimo H, Sugita H (1988) Post-embryonic development of the horseshoe crab. Biol Bull 174: 337-345

Shin PKS, Li HY, Cheung SG (2009) Horseshoe crabs in Hong Kong: current population status and human exploitation. In: Tanacredi JT, Botton ML, Smith DR (eds) Biology and conservation of horseshoe crabs. Springer, New York, NY, p 347-360

Shuster CN Jr (1954) A horseshoe 'crab' grows up. Ward's Natural Sci Bull 28:1-6

Shuster CN Jr (1958) 'Study these', the story of the horseshoe 'crab'. Wilmington Public Schools Staff Reporter 10:4-5

Shuster CN Jr (1982) A pictorial review of the natural history and ecology of the horseshoe crab Limulus polyphemus, with reference to other Limulidae. In: Bonaventura J, Bonaventura C, Tesh S (eds) Physiology and biology of horseshoe crabs: studies on normal and environmentally stressed animals. Alan R Liss, New York, NY, p 1-52

Shuster CN Jr, Sekiguchi K (2003) Growing up takes about ten years and eighteen stages. In: Shuster CN Jr, Barlow RB, Brockmann HJ (eds) The American horseshoe crab. Harvard University Press, Cambridge, MA, p 103-132

Shuster CN Jr, Botton ML, Loveland RE (2003) Horseshoe crab conservation: a coast-wide management plan. In: Shuster CN Jr, Barlow RB, Brockmann HJ (eds) The American horseshoe crab. Harvard University Press, Cambridge, MA, p 358-377

Smith DR, Millard MJ, Carmichael RH (2009) Comparative status and assessment of Limulus polyphemus with emphasis on the New England and Delaware Bay populations. In: Tanacredi JT, Botton ML, Smith DR (eds) Biology and conservation of horseshoe crabs. Springer, New York, NY, p 361-386

Smith SA, Berkson JM (2005) Laboratory culture and maintenance of the horseshoe crabs (Limulus polyphemus). Lab Anim 34:27-34

Tanacredi JT (2001) Horseshoe crabs imperiled? The fate of a species 350 million years in the making. In: Tanacredi JT (ed) Limulus in the limelight: a species 350 million years in the making and in peril? Kluwer Academic/Plenum Publishers, New York, NY, p 7-14

Tsuchiya K (2009) The history of horseshoe crab research and conservation in Japan. In: Tanacredi JT, Botton ML, Smith DR (eds) Biology and conservation of horseshoe crabs. Springer, New York, NY, p 559-570

Tzafrir-Prag T, Lupatsch I, Zarnoch CB, Schreibman MP (2009) Estimation of nutrient requirements for Atlantic horseshoe crabs (Limulus polyphemus: Linnaeus) growth in captivity. In: Tanacredi JT, Botton ML, Smith DR (eds) Biology and conservation of horseshoe crabs. Springer, New York, NY, p 630 (abstract)

van Snik GMJ, van den Boogaart JGM, Osse JWM (1997) 
Larval growth patterns in Cyprinus carpio and Clarias gariepinus with attention to fin fold. J Fish Biol 50: 1339-1352

Yeh HY (1999) Life cycle, juvenile habitat and conservation strategies of the horseshoe crab (Tachypleus tridentatus) in Kinmen. MPhil thesis, National Taiwan University, Taiwan (in Chinese)

Zadeh SS, Christianus A, Saad CR, Hajeb P, Kamarudin MS (2009) Comparisons in prosomal width and body weight

Editorial responsibility: Hans Heinrich Janssen, Oldendorf/Luhe, Germany among early instar stages of Malaysian horseshoe crabs, Carcinoscorpius rotundicauda and Tachypleus gigas in the laboratory. In: Tanacredi JT, Botton ML, Smith DR (eds) Biology and conservation of horseshoe crabs. Springer, New York, NY, p 267-273

Zhou H, Morton B (2004) The diets of juvenile horseshoe crabs, Tachypleus tridentatus and Carcinoscorpius rotundicauda (Xiphosura), from nursery beaches proposed for conservation in Hong Kong. J Nat Hist 38:1915-1925

Submitted: April 8, 2010; Accepted: September 6, 2010

Proofs received from author(s): October 27, 2010 